\title{
A Lexical Account of Implicit (Bound) Contextual Dependence
}

\author{
Richard Breheny \\ University of Cambridge
}

\section{Introduction}

This paper examines some familiar issues concerning implicit contextual restriction. In particular, it considers how the interpretation of expressions such as quantified noun phrases is not determined by explicit material solely and how these expressions get to be implicitly bound-into. To illustrate contextual restriction and implicit binding in QNPs consider that, in certain contexts, (1)a could be understood as in (1)b.

a. Every boy broke every bottle

b. Every boy in the group broke every bottle he was given

I.e, one can imagine a situation where (1)a is uttered and understood according to the paraphrase in (1)b. Here, not only would there be context dependence regarding the domain of quantification for a QNP (as in 'Every boy') but, the interpretation of 'every bottle' would be implicitly dependent on the subject quantifier.

We will consider a number of proposals about how to account for these phenomena. The proposals fall into two categories: linguistic and pragmatic. Linguistic proposals imply that QNPs (for example) can mean different things (have different contents) in different contexts and that, where a QNP is bound into, this fact is represented at the syntactic level. So, for example, in the kind of context for (1), the expression 'every boy' means every boy in the group, while the dependence of the object QNP on the subject is reflected in its syntactic properties as well as its meaning. Pragmatic proposals do not impute any extra meaning to QNPs themselves but suggest that the extra content is added by a mechanism of presupposition accommodation. Also, according to the presupposition proposals we will consider, binding would be handled at the level of presupposition satisfaction and so does not need to be represented at the syntactic level.

Of the linguistic proposals, there are those which find hidden or covert variable expressions in the structure of QNPs and there are variable-free treatments which would have to posit some kind of lexical manipulation.

It will be argued here that a variable-free treatment is best suited to handle the full range of data considered. Some suggestions will also be made as to how to accommodate the required lexical manipulation in current lexicographic theories.

More broadly, the phenomena treated here raise the issue of the relation between context-dependence and bindability and how we should think of the paradigm case embodying these two properties - that of pronouns. The paper will begin and end with some discussion on these latter issues. 


\section{Context Dependence and Bindability}

As context-dependent expressions, QNPs are often thought of in Kaplanian terms according to a semantic rule which specifies their interpretation as a function of some feature of Context. This is basically the proposal of Westerstahl (1985). Unfortunately, Westerstahl did not consider implicit binding in QNPs. Indeed, for any context-dependent expression which seems amenable to a Kaplanian analysis, the same problem seems to arise since any such expression seems to be open to a bound-into interpretation - i.e. dependent on a configurationally superior quantificational expression.

To illustrate, consider that 'tall' and 'finish' are prototypical contextdependent expressions in the relevant sense. These can both receive bound-into interpretations as illustrated in (2) and (3), where the (b) versions represent glosses for the (a) versions in certain imaginable contexts:

a. At the netball tournament, each of the girls playing Goal Defence was tall.

b. At the netball tournament, each $\mathrm{i}_{\mathrm{i}}$ of the girls playing Goal Defence was tall in relation to the members of the age-group she $e_{i}$ was playing under.

(3) a. When John had his house built, every craftsmen finished on time

b. When John had his house built, every craftsmen finished his $_{\mathrm{j}}$ job on time

Indeed, arguably, to the extent that any expression can vary in its interpretation from context to context, it can be subject to a quantificationally dependent interpretation:

(4) a. John's book, chair, car and house are green

b. Everything John owns is green

c. Everything ${ }_{\mathrm{x}}$ John owns is [green for an $\mathrm{x}$ ]

(5) a. John cut the grass, Mary's hair and the bread on Tuesday

b. John cut everything on Tuesday

c. [everything $\mathrm{x}_{\mathrm{x}}\left[\mathrm{John}\left[\mathrm{vP}[\mathrm{v}\right.\right.$,cut in manner appropriate to $\left.\mathrm{x}]\left[{ }_{\mathrm{NP}} \mathrm{X}\right]\right][\mathrm{on}$ Tuesday]]]

So we can ask whether there is any way to extend this Kaplanian account to handle the bound-into cases.

Third person singular pronouns are probably the prototypical exemplar of both context dependence and bindability. On the one hand we have deictic uses of pronouns and on the other we have 'bound-variable' pronouns. One way to unify their analysis would involve exploiting the role of variable assignment functions of straightforward model-theoretic semantics. That is, we could first suppose that pronouns are variable terms of direct reference. We could assume that variable 
assignment functions represent relevant contextual information invoked in a Kaplanian semantic rule for deictic pronouns, as well as playing the usual role in the rule for interpreting variables co-indexed with quantifiers. Thus the different types of pronoun would be the result of the dual use such assignment functions would be put to by the analysis.

Apart from there being a number of potential limitations familiar from the debates over the need for E-type pronouns, it seems that this kind of solution does not generalise so readily to the cases discussed above. To see this, we can consider the case of 'tall'.

Let us assume for the sake of argument that 'tall' is an expression that requires the fixing of a set parameter by the context in order to receive an interpretation (as in 'tall for $\mathrm{X}$ '). Pursuing an analysis along the lines just outlined for pronouns, we could suppose that 'tall' as an expression contains some covert set variable. Then the function representing contextual information will assign that variable a value so that the expression could be evaluated in a given model. Depending on whether we think of 'tall' as a complex expression or not, the evaluation will be via a compositional rule or with the help of a meaning postulate. But now there is a problem with obtaining the bound-into interpretation since the interpretation of the context-dependent expression in (2) and (3) does not depend on a parameter which is of the same type as the individuals in the domain of quantification. Note that sometimes, by happy chance, the value of the parameter and the individuals in the domain of quantification are of the same type. 'Away' arguably means something like 'away from $x$ ':

(6) a. Every mother ensured her child remained at most a few feet away

b. Every ${ }_{i}$ mother ensured her $_{i}$ child remained at most a few feet away from her ${ }_{i}$

Pronouns are another example. But this is not the case for 'tall', 'finish' and many other expressions, including QNPs.

One slightly ad hoc way out for this more traditional approach to quantificational dependence would involve positing not one but two parameters for these expressions, realised as two covert variable components of the relevant expression. The idea would be that one covert variable would be of the type of the individuals in the binding domain and the actual contextual parameter for 'tall' and 'finish' would be fixed in relation to that. So 'tall' looks like [tall $f(x)$ ] once the imperceptible structure is brought to the surface. This 'variable-rich' approach is one favoured by Jason Stanley (see Stanley 2000, Stanley \& Szabo 2001 i.a.). We will consider the details of this kind of account for QNPs below and some of its limitations. It should however be apparent that this kind of treatment requires different versions of 'tall' for different potential types of binding expression (quantifiers over times, situations etc).

The variable-rich approach represents a less-than-pleasing option mostly because it is not motivated by our intuitive understanding of the expressions that can be bound into. At most, 'tall' intuitively means something relative to some kind of 
comparison class, not a comparison class relative to an individual. It seems rather that bindability of context-dependent expressions stems not solely from their meaning but from their being interpreted in the 'context' of a quantifier.

In the next section we will consider how the proposals in Partee (1989) offer some motivation for the relation between context dependence and bindability.

\section{Pragmatic Proposals - Partee (1989) \& Geurts \& van der Sandt (1999)}

One significant feature of Partee's proposals regarding the relation between context dependence and bindability is that it does not involve changing the meaning of 'tall' or 'finish' to a type which contains extra dependencies. Partee achieves the effect in question by invoking a form of presupposition accommodation well known in the dynamic literature.

Partee's pragmatic approach starts with the observation that our contextdependent expressions are 'presuppositional' in a way. Adopting a dynamic framework, such as DRT, Partee supposes that the lexical semantics for the contextdependent expression is stated with reference to some accessible dynamic context (say, DRSs). The example she discusses is given in (7):

\section{Every man who stole a car abandoned it 2 hours later}

According to Partee, the semantics for 'later' would specify that whatever DRS it anchors to, it must have, either overtly or inferably, a reference time to interpret 'later' in terms of. The proposal that the contextually variable parameter be introduced by inference into the anchoring DRS just exploits the mechanism made use of in presupposition accommodation. Her analysis of (7) is given in (8) where the temporal discourse referent, $t_{l}$, in the DRS of the scope and the relation between $t_{l}$ and $x_{1}$ are introduced by an accommodating inference:

$$
\begin{aligned}
& <\emptyset,\left\{<\left\{\mathrm{e}_{1}, \mathrm{t}_{1}, \mathrm{x}, \mathrm{y}\right\},\left\{\operatorname{man}(\mathrm{x}), \operatorname{car}(\mathrm{y}), \operatorname{steal}(\mathrm{x}, \mathrm{y}, \mathrm{e}), \operatorname{at}\left(\mathrm{e}, \mathrm{t}_{1}\right)\right\}>\rightarrow<\left\{\mathrm{e}_{2}\right\},\right. \\
& \left.\left\{2 \text { hours_later }\left(\mathrm{t}_{1}, \mathrm{e}_{2}\right), \operatorname{abandon}\left(\mathrm{x}, \mathrm{y}, \mathrm{e}_{2}\right)\right\}>\right\}>
\end{aligned}
$$

Similar moves could be made in relation to (2) - (6) above. For example, in the 'tall'example, the plural discourse referent $Y$ and the condition, in age group $(x, Y)$ could be pragmatically introduced into the restrictor DRS, providing a variable value for the contextual parameter of 'tall' in relation to the quantificational domain:

$$
<\varnothing,\left\{<\{x, Y\},\{\text { girl_in_GD(x), age_group }(x, Y)\}>\rightarrow<\varnothing,\left\{\operatorname{tall} \_f o r(x, Y)\right\}>\right\}>
$$

A proposal to deal with contextual restriction of QNPs along these lines, has been made by Geurts and van der Sandt (1999). They propose that the restriction of a QNP behaves like a presupposition trigger, and needs to be accommodated into some superior DRS-type structure. Although they do not deal directly with implicit binding of QNPs, one can make an interpolation of their account of (10)a under the 
construal in (10)b. This is given in (10)c which represents the result of accommodating the presupposition associated with 'every waiter' in the scope DRS':

(10) a. Every hostess thanked every waiter

b. Every hostess thanked every waiter she hired

c. $<\varnothing, \quad\{<\{\mathrm{x}, \mathrm{y}\},\{\operatorname{hostess}(\mathrm{x}), \quad$ waiter(y), $\operatorname{hired}(\mathrm{x}, \mathrm{y})\}>\rightarrow<\varnothing$, $\{$ thanked $(\mathrm{x}, \mathrm{y})\}>\}>$

Thus the relation between context dependence and bindability is explained as arising due to the fact that, in DRT, the 'context' for a presuppositional expression may not be the global DRS but some intermediate, accessible DRS. It is notable that this proposal accounts for the bindability of QNPs and other context-dependent expressions in the same way that it accounts for the bindability of pronouns, since pronouns are just treated as presupposition triggers in the DRT analysis (see van der Sandt 1992, Geurts 1995).

While the DRT-presuppositional treatment links context dependence and bindability in a satisfying way, we will see shortly that it has some limitations. First we need to go over some of the details of the two linguistic alternatives.

\section{The Variable-Rich Account (Stanley 2000 \& Stanley \& Szabo 2001)}

As mentioned in Section 2, the variable-rich account has been advocated most vocally by Jason Stanley. Stanley (2000) insists that no bound-into interpretations are possible without there being some kind of syntactic reflex in the form of a variablelike element. This is usually covert. Stanley \& Szabo's (2001) proposal for QNP syntax and semantics is given in (11):

$$
\begin{aligned}
& \text { a. } \quad\left[\text { DP every }\left[{ }_{N P}\left[{ }_{N}<\text { guest, } \mathrm{f}(\mathrm{x})>\right]\right]\right] \\
& \text { b. } \quad \llbracket<\text { guest, } \mathrm{f}(\mathrm{x})>\rrbracket^{\mathrm{c}}=\llbracket \text { guest } \rrbracket^{\mathrm{c}} \cap \llbracket \mathrm{f} \rrbracket^{\mathrm{c}}\left(\llbracket \mathrm{x} \rrbracket^{\mathrm{c}}\right)
\end{aligned}
$$

Elsewhere, Stanley (2002) proposes that predicational 'tall' has a covert nominal (with bindable variable) as part of its structure. In general, a bindable expression like 'home' is proposed to have a variable present in the syntactic structure:

$$
\begin{aligned}
& \text { a. Everyone went home } \\
& \text { b. } \quad\left[\text { Everyone }_{i}\right][\text { went }[<\text { home, } f(i)>]]
\end{aligned}
$$

In favour of the covert variable view Stanley (2000) points to various syntactic facts which suggest a similarity in behaviour between expressions which are implicitly bindable and pronouns. Most notably, there is supposedly a similarity in weak crossover behaviour. That is, just as it seems to be less than fully acceptable to use sentences like (13)a, (14)a and (15)a intending that the object noun phrase take scope over and bind into the subject noun phrase, so it seems to be less than acceptable to try the same with the $(b)$ cases: 
(13) a. * Her $_{i}$ waiters were thanked by every $y_{i}$ hostess

b. * Every waiter ${ }_{i}$ was thanked by every ${ }_{i}$ hostess

(14) a. * Her $_{i}$ local bar sponsored every reporter $^{*}$

b. * A local $_{\mathrm{i}}$ bar sponsored every reporter $_{\mathrm{i}}$

(15) a. * Her $_{i}$ trip home made every ${ }_{i}$ reporter nervous

b. * The $_{\mathrm{i}}$ trip home made every ${ }_{\mathrm{i}}$ reporter nervous

In both types of case, the expression which is meant to be bound into c-commands the binding expression at the surface level. Further evidence that binding dependencies in QNPs are constrained by 'syntactic' rules similar to those which regulate the distribution of bound variable readings of pronouns is provided in Marti (this volume). Assuming that weak-crossover and such phenomena have to do with constraints on co-indexing of variable-like expressions with binding quantificational expressions at the surface level of syntactic representation, we can take this data as evidence for the variable rich account. However, the phenomenon can also be accommodated within an approach to binding dependencies which does not assume that the bound into expressions are or contain variable elements. This is the variablefree approach, to be considered below. What both variable-rich and variable-free treatments can both capture is the constraint on the configurational relation between binder and bindee. Surface configurational constraints cannot be directly captured by the DRT-presupposition account.

\section{Variable-Free Accounts of Binding (Jacobson 1999 i.a)}

In a variable-free framework such as Jacobson's ${ }^{2}$, an expression which is to be bound into contains no variable-like constituents but is marked as such in its category label (with corresponding semantic-type change). An expression which is to be bound into by a quantifier over individuals is $\mathrm{A}^{\mathrm{NP}}$, where NP is the category of expressions of type $<\mathrm{e}>$. So if $\mathrm{A}$ is a category of type $<\mathrm{a}>$ expressions, then $\mathrm{A}^{\mathrm{NP}}$ is a category of type $<\mathrm{e}, \mathrm{a}>$ expressions. Binding dependencies are passed up by the Geach-rule stated in (16)a (taken from Jacobson 1999: 131) where the dependency is of category $C$ and type $c$. (16)b defines the operation on the syntactic category of the geached expression while (16)c describes how the semantic interpretation is shifted:

(16) a. Let $\alpha$ be an expression of the form: $\langle/ \alpha /$; $\mathrm{A} ; \alpha\rangle$. There is a corresponding expression $\beta$ of the form: $</ \alpha / ; \mathbf{g}_{\mathrm{C}}(\mathrm{A}) ; g_{c}\left(\alpha^{\prime}\right)>$, for $C$ any syntactic category and $c$ the corresponding semantic type.

b. $\quad g_{C}(B / A)=\left(B^{C} / A^{C}\right)$

c. If $\mathrm{f}$ is a function of type $<\mathrm{a}, \mathrm{b}>$ then $\mathrm{g}_{\mathrm{c}}(\mathrm{f})$ is a function of type $<<\mathrm{c}, \mathrm{a}>,<\mathrm{c}, \mathrm{b}>>$, where $\left.\left.\left.\mathrm{g}_{\mathrm{c}}(\mathrm{f})=\lambda \mathrm{V}[\lambda \mathrm{C}[\mathrm{f}(\mathrm{VC})))\right)\right]\right]$

$V$ is type $<\mathrm{c}, \mathrm{a}>$; $C$ is type $<\mathrm{c}>$ 
A pronoun which is to be bound is analysed by Jacobson as category $\mathrm{NP}^{\mathrm{NP}}$ and type $<\mathrm{e}, \mathrm{e}>$. If we wish to analyse 'likes him' with a dependent pronoun then we need to apply the geach rule to 'likes' so that the dependency can be passed up to some higher level at which binding takes place. The transformation is shown in (17)a. (17)b,c spell out the syntax and semantics for bindable 'him' and the whole phrase:

$$
\begin{aligned}
& \text { a. } \quad \text { /likes/; (S/NP)/NP; likes' } \Rightarrow_{g} \text { /likes/; (S/NP) }{ }^{\mathrm{NP}} / \mathrm{NP}^{\mathrm{NP}} ; \mathrm{g}_{\mathrm{e}}(\text { likes }) \\
& \text { b. him; } \mathrm{NP}^{\mathrm{NP}} ; \lambda \mathrm{x}[\mathrm{x}] \\
& \text { c. likes him; }(\mathrm{S} / \mathrm{NP})^{\mathrm{NP}} ; \lambda \mathrm{f}\left[\lambda \mathrm{y}\left[\operatorname{likes}^{\prime}(\mathrm{f}(\mathrm{y}))\right]\right](\lambda \mathrm{x}[\mathrm{x}])=\lambda \mathrm{x}\left[\operatorname{likes}^{\prime}(\mathrm{x})\right]= \\
& \text { likes' }
\end{aligned}
$$

Binding itself is effected by the z-rule at the level of the constituent to which it applies. This is stated in (18) (ibid: 133):

(18) a. Let $\alpha$ be an expression of the form: $</ \alpha /,(\mathrm{B} / \mathrm{NP}) / \mathrm{A}, \alpha^{3}>$. Then there is a corresponding expression $\beta$ of the form: $\left.</ \alpha /, \mathbf{z}_{\mathrm{B}}(\mathrm{B} / \mathrm{NP}) / \mathrm{A}\right)$, $z_{b}\left(\alpha^{\prime}\right)>$, for $b$ the semantic type for category $B$.

b. $\quad \mathbf{z}_{\mathrm{B}}((\mathrm{B} / \mathrm{NP}) / \mathrm{A})=(\mathrm{B} / \mathrm{NP}) / \mathrm{A}^{\mathrm{NP}}$

c. Let $\mathrm{f}$ be a function of type $<\mathrm{a},<\mathrm{e}, \mathrm{b}>>$. Then $\mathbf{z}_{\mathrm{b}}(\mathrm{f})$ is a function of type $<<e, a>,<e, b>>$ such that:

$$
\mathbf{z}_{\mathbf{b}}(\mathrm{f})=\lambda \mathrm{V}[\lambda \mathrm{x}[\mathrm{f}(\mathrm{V}(\mathrm{x}))(\mathrm{x})]] \quad(\text { for } \mathrm{V} \text { a variable of type }<\mathrm{e}, \mathrm{a}>)
$$

The z-rule works by transforming an expression wanting two arguments so that the transformed expression takes a dependent expression as first argument and binds the incoming dependency to the second argument. Eg, consider (19)a on a 'boundvariable' construal. The form of 'Mary likes him' is given in (19)b. The result of applying the z-rule to 'thinks' is in (19)c. Combining (19)b and (19)c yields (19)d:

$$
\begin{aligned}
& \text { a. Every boy thinks Mary likes him } \\
& \text { b. } \quad<\text { /mary likes him/, } \mathrm{S}^{\mathrm{NP}}, \lambda \mathrm{x}\left[\text { likes' }^{\prime}(\mathrm{x})(\mathrm{m})\right]> \\
& \text { c. } \quad</ \text { thinks/, (S/NP)/S } \mathrm{S}^{\mathrm{NP}}, \lambda \mathrm{P}[\lambda \mathrm{y}[\text { thinks'(P(y))(y)] }> \\
& \text { d. } \quad</ \text { thinks mary likes him/, S/NP, } \\
& \left.\lambda \mathrm{P}\left[\lambda \mathrm{y}\left[\text { thinks' }^{\prime} \mathrm{P}(\mathrm{y})\right)(\mathrm{y})\right]\right]\left(\lambda \mathrm{x}\left[\text { likes' }^{\prime}(\mathrm{x})(\mathrm{m})\right]\right)> \\
& =</ \text { thinks mary likes him/, S/NP, } \lambda \mathrm{y}\left[\operatorname{thinks}^{\prime}\left(\operatorname{likes}^{\prime}(\mathrm{y})(\mathrm{m})\right)(\mathrm{y})\right]>
\end{aligned}
$$

As Jacobson (1999) observes, if weak cross-over effects are sensitive to surface configurational relations, these can be captured by blocking any version of the z-rule which has the effect of binding a dependent expression to a lower argument slot.

So, in a variable-free grammar, expressions which are bound into by higher expressions are marked as dependent at the level of syntax and semantics. The rules for binding, weak cross-over and other relevant phenomena can all make reference to expressions of this type of category or the operators involved in binding.

Turning now to binding into context dependent expressions, Jacobson (1999:145) briefly suggests that examples such as in (2) - (3) above can be handled by some kind of 'shifting' rule. That is, where an expression such as 'tall' is 
interpreted as bound-into, then that expression shifts into a dependent expression (with category of the form $\mathrm{A}^{\mathrm{NP}}$ ).

One can only assume that the shifting in question is an operation performed at the lexical level, given the amount of contentful lexical semantic manipulation required. However, about dependencies formed in noun phrases, such as in (1), Jacobson (ibid) suggest that the shifting may take place at the level of complex phrases. This seems to be less than satisfactory for reasons to do with compositionality. Shifting operations which are part of the combinatronics of the grammar ought to have statable semantic effects. The shifting that goes on for 'every bottle' in (1) above has an effect that is determined in part by the context. I.e., that the expression ends up meaning $\lambda x \lambda P[\operatorname{every}(\lambda y[$ bottle $(y) \wedge$ was given $(y)(x)])(P)]$ could not be determined in advance by a semantic rule which does not itself make reference to features of context. So the semantic component of any combinatronic shifting rule for this purpose would itself have to be context dependent. As Stanley \& Szabo (2001) argue in relation to a similar proposal, this would make the grammar less than fully compositional. ${ }^{3}$ Below, a general lexical account of this kind of shifting will be offered such that the QNP cases can be handled without impugning compositionality.

To sum up so far: Though implicit adjustment of content is possible at the pragmatic level of presupposition accommodation, it seems that, at least where expressions are bound-into, there needs to be a reflex of this fact at the syntactic level. This raises problems for the DRT-based accounts. Both variable-rich and variable-free accounts make allowance for this, though there are some grey areas for both. These include Stanley's contention that all expressions which can be bound into ipso facto have hidden variables. Regarding the variable-free account, what more, if anything, can we say about this 'shifting' process mentioned?

\section{Multiple Dependencies and Other Problems}

One issue for the variable-rich account of bindable context dependencies (mentioned above) is that where the expression is not bound into, there is nothing intuitively that we can assume the individual variable has as its value. For instance, if we take a case where (20)a is understood as in (20)b, we might wonder what value context has assigned to the individual variable associated with the complex variable expression Stanley \& Szabo associate with every QNP (shown in (20)c):
a. Every student passed
b. Every student in John's class this year passed
b. $\quad[[$ Every $[<$ student, $\mathrm{f}(\mathrm{x})>]][$ passed] $]$

Stanley \& Szabo suggest it is the speaker, but this seems a little ad hoc.

Another problem for S\&S's particular proposal concerns intensional modification in QNPs since the contextual restriction sometimes appears inside, (21), and sometimes outside, (22), the scope of these modifiers: 
(21) a. Every former girlfriend of Bill was asked to leave.

a'. Every [[former girlfriend of Bill] at the party] was asked to leave.

b. Every fake diamond was traced to its original vendor.

b'. Every [[fake diamond] we discovered] was traced to its original vendor.

(22) a. Our boss sends every former employee a Christmas card.

b. Our boss sends every [former [employee of our company]] a Christmas card.

Worse still, it is possible that there can be more than one implicit quantificational dependency. In an appropriate situation, 'every ${ }_{z}$ mistake' in (23)a can be understood as indicated in the gloss in (23)b. This can happen in a context where students write a number of papers which are each marked by three examiners:

(23) a. Every $x_{x}$ student was feeling particularly lucky and thought no examiner would notice every ${ }_{z}$ mistake

b. $\quad$ Every $_{\mathrm{x}}$ student thought no ${ }_{\mathrm{y}}$ examiner would notice every ${ }_{\mathrm{z}}$ [mistake made on a paper $x$ turned in and $y$ examines]

Moreover, it is not difficult to imagine an appropriate context for (24)a below which results in one bound dependency inside the scope of the intensional operator and one outside, as suggested in (24)b. For example, imagine a context where art dealers are entirely scrupulous but, due to the long-term effects of absinthe, many famous artists have become paranoid; in particular, they each imagine that the otherwise scrupulous dealers are out to ruin the market value of just their paintings.

(24) a. Every ${ }_{x}$ paranoid artist thinks no ${ }_{y}$ dealer will stop at selling every forged painting.

b. Every ${ }_{x}$ paranoid artist thinks no ${ }_{y}$ dealer will stop at selling every ${ }_{z}$ [[forged [painting by $\mathrm{x}]$ ] coming into y's possession].

For (25)a both dependencies could be outside the scope of 'former'. For (25)b both could be inside the scope of 'counterfeit' in easily imaginable contexts:

(25) a. Every ${ }_{x}$ parole officer doesn't expect every $y_{y}$ potential employer to spot every ${ }_{z}$ former convict.

a'. $\quad$ Every $_{\mathrm{x}}$ parole officer doesn't expect every $\mathrm{y}_{\mathrm{y}}$ potential employer to spot every $_{2}[[$ former convict $]$ under x's care \& applying to y for a job] $]$.

b. Every $y_{x}$ government makes allowance for the fact that no ${ }_{y}$ type of

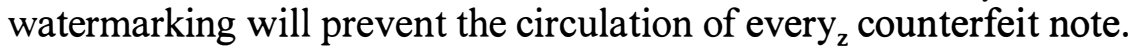

b'. $\quad$ Every $_{\mathrm{x}}$ government makes allowance for the fact that no ${ }_{\mathrm{y}}$ type of watermarking will prevent the circulation of every $_{z}$ [counterfeit [note of currency of $x$ marked by $y]$. 
(26)a could perhaps be understood as in (26)b or (26)c:

(26) a. Every company knows that none $_{\mathrm{y}}$ of the pension fund can be diverted away from any $y_{z}$ former employee

b. Every ${ }_{x}$ company knows that none ${ }_{y}$ of the pension fund can be diverted away from any $y_{z}[[$ former [employee of $x]]$ who is due some of $y$ ]

c. Every $y_{x}$ company knows that none ${ }_{y}$ of the pension fund can be diverted away from $\operatorname{any}_{z}$ [former [employee of $\mathrm{x}$ who contributed to $\mathrm{y}$ ]]

If we wanted to pursue a variable-rich approach, given these multiple dependencies, we seem to need to assume that QNP structures contain a plethora of hidden variables at different levels which are vacuously assigned (to what?) when not used.

These kinds of multiple-bound examples are also problematic for the Partee/Geurts \& van der Sandt proposals. Consider that, for example, we can represent the intended interpretation of (23) using something like the DRS in (27):

$$
\begin{aligned}
& <\varnothing, \quad\{<\{\mathrm{x}, \mathrm{y}, \mathrm{u}\}, \quad\{\operatorname{student}(\mathrm{x}), \quad \text { examiner(y), } \operatorname{paper}(\mathrm{u}), \quad \text { wrote }(\mathrm{x}, \mathrm{u}), \\
& \operatorname{marked}(\mathrm{y}, \mathrm{u})\}>\rightarrow<\{\mathrm{p}\},\{\operatorname{think}(\mathrm{x}, \mathrm{p}), \mathrm{p}:<\emptyset,\{<\{\mathrm{v}\},\{\mathrm{v}=\mathrm{y}\}>\rightarrow \neg<\varnothing,\{<\{\mathrm{z}\}, \\
& \{\text { mistake(z), on }(\mathrm{z}, \mathrm{u})\}>\rightarrow<\varnothing,\{\text { notice }(\mathrm{v}, \mathrm{z})\}>\}>\}>\}>\}> \\
& =<\varnothing,\{<\{\mathrm{x}, \mathrm{y}, \mathrm{u}\}, \quad\{\operatorname{student}(\mathrm{x}), \operatorname{examiner}(\mathrm{y}), \operatorname{paper}(\mathrm{u}), \quad \text { wrote }(\mathrm{x}, \mathrm{u}) \text {, } \\
& \operatorname{marked}(\mathrm{y}, \mathrm{u})\}>\rightarrow<\text { p }\},\{\operatorname{think}(\mathrm{x}, \mathrm{p}), \mathrm{p}: \neg<\varnothing,\{<\{\mathrm{z}\},\{\operatorname{mistake}(\mathrm{z}), \text { on }(\mathrm{z}, \mathrm{u})\}> \\
& \rightarrow<\emptyset,\{\text { notice }(\mathrm{v}, \mathrm{z})\}>\}>\}>\}>
\end{aligned}
$$

It seems that, in G\&vdS's terms, the presupposition of the QNP 'every mistake' would have to have been accommodated partly at the level of the highest DRS and partly at the most local level. This may not be obvious on a brief inspection of (27). But note that in order to link the examiners to the right mistakes, we need to introduce some assumptions concerning how mistakes turn up on papers students wrote. So the accommodation for 'every mistake' involves the discourse referent $u$ and the conditions paper $(u)$, wrote $(x, u)$ and $\operatorname{marked}(y, u)$ in addition to the lower conditions mistake(z) and on $(z, u)$. This splitting of presuppositions seems problematic for a number of reasons. The most pressing issue concerns whether accommodations should be allowed to be distributed across a DRS in this way. Also, we have the familiar problem of why the whole presupposition should not have been accommodated globally - as would be dictated by the principles of presupposition G\&vdS propose. It is noticeable that their 'accommodate most globally' principle would get things right in the 'pessimistic' student example in (28)a, whose DRS would be (28)b. Here the whole of the accommodation for 'every mistake' appears at the highest plausible level:

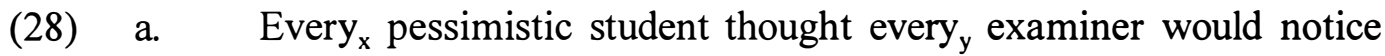
every $_{z}$ mistake 
b. $\quad<\{\mathrm{x}, \mathrm{y}, \mathrm{z}, \mathrm{u}\}, \quad\{\operatorname{student}(\mathrm{x}), \quad$ examiner(y), $\operatorname{paper}(\mathrm{u}), \quad \operatorname{wrote}(\mathrm{x}, \mathrm{u})$, $\operatorname{marked}(\mathrm{y}, \mathrm{u}), \operatorname{mistake}(\mathrm{z}), \operatorname{on}(\mathrm{z}, \mathrm{u})\}>\rightarrow<\{\mathrm{p}\},\{\operatorname{think}(\mathrm{x}, \mathrm{p}), \mathrm{p}:<\oslash$, $\{<\{\mathrm{v}\}, \quad\{\mathrm{v}=\mathrm{y}\}>\rightarrow \quad<, \quad\{<\{\mathrm{w}\}, \quad\{\mathrm{w}=\mathrm{z}\}>\rightarrow<\varnothing$, $\{\operatorname{notice}(\mathrm{v}, \mathrm{w})\}>\}>\}>\}>$

$=<\{\mathrm{x}, \mathrm{y}, \mathrm{z}, \mathrm{u}\}, \quad\{\operatorname{student}(\mathrm{x}), \operatorname{examiner}(\mathrm{y}), \operatorname{paper}(\mathrm{u}), \quad$ wrote $(\mathrm{x}, \mathrm{u})$, $\operatorname{marked}(\mathrm{y}, \mathrm{u}), \operatorname{mistake}(\mathrm{z}), \operatorname{on}(\mathrm{z}, \mathrm{u})\}>\rightarrow<\{\mathrm{p}\},\{\operatorname{think}(\mathrm{x}, \mathrm{p}), \mathrm{p}:<\varnothing$, $\{\operatorname{notice}(\mathrm{y}, \mathrm{z})\}>\}>$

\section{Proposal Involving Lexical Manipulation}

Thus far we have considered evidence which weighs against both the variable-rich and the dynamic-presupposition approaches. In this section, some of the details required to give a plausible variable-free account will be explored.

It was suggested above that where implicit binding occurs with complex QNPs, it would be less than optimal to have the 'shifting' of these expressions occur at the level of the complex phrase. In this section, some general proposals for handling context dependence and implicit binding will be given. These proposals only involve lexical manipulation. It will then be demonstrated how the QNP cases discussed above can be handled given the proposed innovations in the lexicon. It should be stressed here that the proposals about the lexicon are very schematic. They are just meant to give some idea of how various constraints on shifting might be stated. The essential feature of the proposal being made is that the grammar can allow for pragmatics to affect lexical interpretation.

\subsection{Ad hoc restriction of lexical interpretation}

Looking over the data relating to context dependence and bindability, it is tempting to suppose that the following two generalisations hold for natural languages:

(i) Any lexical expression can express an ad hoc contextually restricted meaning

(ii) Any lexical expression of category A can be 'shifted' into category $\mathrm{A}^{\mathrm{NP}}$

If these are correct, then the mechanism that results in (ii) would seem to depend on the mechanism responsible for (i) since, as we have seen, ad hoc lexical semantic content needs to be provided to relate the value of a shifted expression to elements in the binding domain. One can explore what kinds of relationships may be involved through some kind of flexible-lexicon framework.

Current work in the generative lexicon literature goes beyond the original overly 'modular' lexicon of Pustejovsky (1995) since it is now acknowledged that it is necessary to allow for contextual manipulation of lexical interpretation. This apparent penetration of the grammar by pragmatics can be achieved without impugning strict modularity in the lexicon through the use of defaults (see Copestake \& Lascarides 1999, Lascarides \& Copestake 1998). The idea is that some components of an expression's meaning fixed by the grammar may only be default 
components. I.e. they are subject to modification if context, including discourse principles and world knowledge, dictates.

In order to accommodate the possibility that any expression may receive a contextually restricted interpretation, one might simply posit 'wild-card' qualia. The values given wild-card qualia would potentially restrict the extension of the word's interpretation in a given context. Wild cards could be inserted into any lexical semantic representation. A wild-card attribute would be fixed at a default uninformative value, say the least upper bound of the local inheritance lattice. But as it is only default, this value can be overridden by context. The idea is illustrated in the box below. For the original example in (1), the default value, thing, of the wild card attribute for 'boy' would be overridden by context so that quantification is only over boys in the contextually salient group.

\begin{tabular}{ll|}
\hline boy & \\
ARGSTR $=$ & ARG $1=[\mathbf{z}]$ human \\
$\ldots$ & \\
QUALIA $=$ & $\ldots$ \\
& WILD $=[z]$ thing \\
\hline
\end{tabular}
necessarily express the so-called lexical concepts that are associated with them. Rather, words could be conceived as constituents of utterances, used to characterise some component of what is being described. The interpretations of words therefore are more like ad hoc characterisations of descriptive acts. These interpretations are normally constrained by the contents of the lexical concepts, but they are not necessarily identical to the lexical conceptual contents. Hence, the structure for the representation of a word's interpretation would only include the structure for the lexical concept as a part. Wild-card qualia thus represent contextually supplied features of a word's semantic interpretation which exist at the same level as the qualia of the lexical concept's semantic representation.

Although somewhat radical, this approach could be extended to give an account of the interpretation of 'finish' and 'tall'. It is particularly apparent from the critique of Pustejovsky by Fodor and Lepore (1998) that at least 'finish' may be associated with a lexical concept which just means finish. In that case, wild-card qualia inserted with the use of 'finish' would be fixed so as to narrow down exactly what is being finished in the context. One could go further and argue that 'tall' is associated with a very weak lexical concept which just means tall relative to some criterion. Again, the use of the expression would be interpreted to mean something stronger through the contextual fixing of wild-cards. Note that with these very weak meanings, we would expect the use of these words to invariably trigger contextual narrowing since this would be required by discourse/conversational principles of coherence or relevance. As such, these expressions would be 'presuppositional' but the presupposition would not need to be lexically encoded as it would turn on considerations of usage.

Whether all intuitively context-dependent expressions can be handled in this 
way is an open question. But if so, it would mean that the scope of Pustejovsky's modular programme would become more limited to genuine polysemy (as with 'window' etc), intensional modification and to constraints on lexical manipulation touched on briefly in the next sub-section.

\subsection{The D-rule}

When it comes to shifting a category A expression into a category $\mathrm{A}^{\mathrm{NP}}$ expression, an extra argument needs to be added. We can posit a lexical rule, the D-rule, which creates new lexical items from old with additions to the argument structure and the qualia structure. The lexical semantic manipulation required to interpret 'mistake' in (23) is illustrated in the boxes below. The sequence of the first two boxes, (29)a,b, show one application of the D-rule to the standing lexicographic structure for 'mistake'. Generative lexical rules would need to ensure that the feature type of the new argument matches the feature type of the head noun of the binding domain. General lexical constraints could also determine such things as argument hierarchy (agents above artefacts) and the default value of the added wild-card qualia. Two applications of the D-rule will produce an expression of category $\left(\mathrm{CN}^{\mathrm{NP}}\right)^{\mathrm{NP}}$ and type $<e,<e,<e, t>>>$. The relevant structure is shown in (30)a. (30)b below is suggestive of the outcome of context overriding the default values of the wild-cards:

(29)

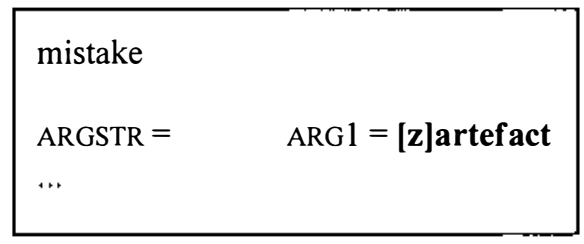

(30)

a.

$$
\begin{aligned}
\text { mistake }_{\text {dd }} & \\
\text { ARGSTR }^{2} & \\
\text { ARG } 1 & =[\mathbf{x}] \text { agent } \\
\text { ARG2 } & =\text { [y] agent } \\
\text { ARG3 } & =[\mathbf{z}] \text { artefact } \\
\ldots \quad & \\
\text { QUALIA }= & \ldots \\
\text { WILD } & =\mathrm{R}([\mathrm{x}],[\mathrm{z}]) \\
\text { WILD } & =\mathrm{R}([\mathrm{y}],[\mathrm{z}])
\end{aligned}
$$

b.

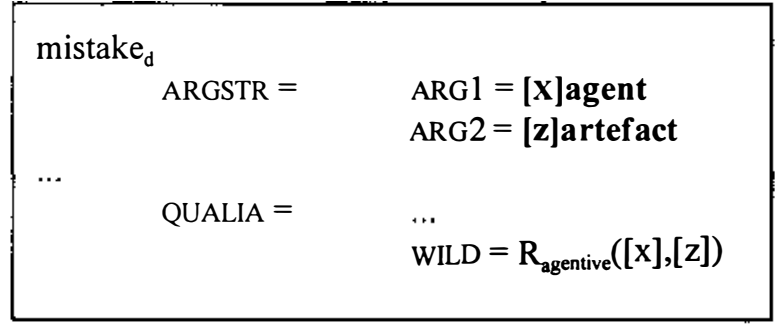

$$
\begin{aligned}
& \text { mistake }_{\text {dd }} \\
& \text { ARGSTR = } \\
& \text { ARG1 }=[\mathbf{x}]: \text { agent } \\
& \text { ARG2 }=[\mathbf{y}]: \text { agent } \\
& \text { ARG3 }=[\mathbf{z}]: \text { artefact } \\
& \begin{aligned}
\text { QUALIA }= & \quad \ldots \\
\text { WILD } & =\text { made }([\mathbf{x}],[\mathbf{z}]) \\
\text { WILD } & =\text { in_paper_examined_by }([\mathbf{z}],[\mathbf{y}])
\end{aligned}
\end{aligned}
$$

\subsection{Deriving Implicit Binding in QNPs}

Abstracting away from these lexicographic details, we can represent the results of the two types of lexical manipulation for the common noun heads in our original example, (1), as in (31). That is, we assume that for both the common nouns 'boy' 
and 'bottle' some lexical manipulation has occurred and that this manipulation has been constrained by context. The interpretation for the original example is represented in (32)c where $\uparrow$ is a standard type-shifting operator and the subscripts have been left off the operators $g$ and $z$ :
a. $\quad$ boy $_{\mathrm{c}}{ }^{\prime}=\lambda \mathrm{x}\left[\right.$ boy' $\left.^{\prime}(\mathrm{x}) \wedge \mathrm{C}^{\prime}(\mathrm{x})\right]$
b. $\quad$ bottle $_{\mathrm{d}}{ }^{\prime}=\lambda \mathrm{y}\left[\lambda \mathrm{x}\left[\right.\right.$ bottle' $\left.\left.^{\prime}(\mathrm{x}) \wedge \mathrm{C}(\mathrm{x}, \mathrm{y})\right]\right]$
a. Every boy broke every bottle
b. Every boy in the group broke every bottle he was given
c. $\quad$ every' $\left(\right.$ boy $\left._{c}{ }^{\prime}\right)\left(z(\uparrow\right.$ broke $)\left(g\left(\right.\right.$ every'$\left.^{\prime}\right)\left(\right.$ bottle $\left.\left.\left._{\mathrm{d}}{ }^{\prime}\right)\right)\right)$

Regarding intensional adjectives, these can be subject to contextual restriction suggested in (33)b. They can also be subject to the D-rule - as per (33)c. Thus where (34)a gets an interpretation glossed in (34)b, this could be represented as in (34)c:
a. $\quad$ fake' $=\lambda \mathrm{P}[\lambda \mathrm{x}[\neg \mathrm{P}(\mathrm{x}) \wedge \mathrm{R}(\mathrm{x})]]$
$\{R$ is a grammatically specified resemblance-to- $P$ relation $\}$
b. $\quad$ fake $_{\mathrm{c}}{ }^{\prime}=\lambda \mathrm{P}[\lambda \mathrm{x}[\neg \mathrm{P}(\mathrm{x}) \wedge \mathrm{R}(\mathrm{x}) \wedge \mathrm{C}(\mathrm{x})]]$
c. $\quad$ fake $_{\mathrm{d}}{ }^{\prime}=\lambda \mathrm{y}\left[\lambda \mathrm{P}\left[\lambda \mathrm{x}\left[\neg \mathrm{P}(\mathrm{x}) \wedge \mathrm{R}(\mathrm{x}) \wedge \mathrm{C}^{\prime}(\mathrm{x})(\mathrm{y})\right]\right]\right]$
$\left\{C\right.$ and $C^{\prime}$ are the values of a wild-card attribute $\}$

(34) a. Every gem dealer sold every fake diamond

b. Every gem dealer being set up by the FBI sold every fake diamond he obtained

c. $\quad$ every' $\left(\right.$ gem_dealer $\left._{c}{ }^{\prime}\right)\left(\mathrm{z}\left(\uparrow^{\dagger}\right.\right.$ sold $\left.^{\prime}\right)\left(\mathrm{g}\left(\right.\right.$ every'$\left.^{\prime}\right)\left(\mathrm{g}\left(\uparrow\right.\right.$ diamond $\left.^{\prime}\right)\left(\right.$ fake $\left.\left.\left.\left._{\mathrm{d}}{ }^{\prime}\right)\right)\right)\right)$

Some elaboration on what (34)c means is given in (35) to (39)

$$
\begin{aligned}
& \text { a. } \quad \text { diamond' }^{\prime}=\lambda \mathrm{F}\left[\mathrm{F}\left(\text { diamond' }^{\prime}\right)\right] \quad(F \text { is type }<<\mathrm{e}, \mathrm{t}>,<\mathrm{e}, \mathrm{t}>>) \\
& \text { b. } \left.\quad \mathrm{g}\left(\uparrow \text { diamond' }^{\prime}\right)=\lambda \mathrm{V}\left[\lambda \mathrm{x}\left[\uparrow \text { diamond' }^{2} \mathrm{~V}(\mathrm{x})\right)\right]\right](V \text { is }<\mathrm{e},<<\mathrm{e}, \mathrm{t}>,<\mathrm{e}, \mathrm{t}>>>) \\
& \mathrm{g}\left(\uparrow \text { diamond' }^{\prime}\right)\left(\text { fake }_{\mathrm{d}}{ }^{\prime}\right)=\lambda \mathrm{y}\left[\uparrow \text { diamond' }^{\prime}(\lambda \mathrm{P}[\lambda \mathrm{x}[\neg \mathrm{P}(\mathrm{x}) \wedge \mathrm{R}(\mathrm{x}) \wedge \mathrm{C}(\mathrm{x})(\mathrm{y})]])\right] \\
& =\lambda \mathrm{y}[\lambda \mathrm{F}[\mathrm{F}(\text { diamond })](\lambda \mathrm{P}[\lambda \mathrm{x}[\neg \mathrm{P}(\mathrm{x}) \wedge \mathrm{R}(\mathrm{x}) \wedge \mathrm{C}(\mathrm{x})(\mathrm{y})]])] \\
& =\lambda \mathrm{y}[\lambda \mathrm{x}[\neg \operatorname{diamond}(\mathrm{x}) \wedge \mathrm{R}(\mathrm{x}) \wedge \mathrm{C}(\mathrm{x})(\mathrm{y})]]
\end{aligned}
$$

$\mathrm{g}\left(\right.$ every'$\left.^{\prime}\right)\left(\mathrm{g}\left(\uparrow\right.\right.$ diamond $\left.^{\prime}\right)\left(\right.$ fake $\left.\left._{\mathrm{d}}{ }^{\prime}\right)\right)=\lambda \mathrm{y}\left[\lambda \mathrm{P}\left[\right.\right.$ every' $^{\prime}(\lambda \mathrm{x} . \neg$ diamond $\mathrm{x}) \wedge \mathrm{R}(\mathrm{x}) \wedge$ $\mathrm{C}(\mathrm{x})(\mathrm{y}))(\mathrm{P})]]$

$$
\begin{aligned}
& \mathrm{z}\left(\uparrow^{\uparrow} \text { sold }{ }^{\prime}\right)=\lambda \mathrm{V}\left[\lambda \mathrm{x}\left[\lambda \mathrm{Q}\left[\lambda \mathrm{z}\left[\mathrm{Q} \lambda \mathrm{y} \cdot \operatorname{sold}^{\prime}(\mathrm{y})(\mathrm{z})\right]\right](\mathrm{V}(\mathrm{x}))(\mathrm{x})\right]\right](V \text { is }<\mathrm{e},<<\mathrm{e}, \mathrm{t}>, \mathrm{t} \gg>) \\
& \mathrm{z}\left(\uparrow^{\dagger} \text { sold') }\left(\mathrm{g}\left(\text { every’}^{\prime}\right)\left(\mathrm{g}\left(\uparrow \text { diamond' }^{\prime}\right)\left(\text { fake }_{\mathrm{d}}{ }^{\prime}\right)\right)\right)\right. \\
& =\lambda \mathrm{x}\left[\lambda \mathrm { Q } [ \lambda \mathrm { z } [ \mathrm { Q } \lambda \mathrm { y } [ \operatorname { s o l d } ^ { \prime } ( \mathrm { y } ) ( \mathrm { z } ) ] ] ] \left(\lambda \mathrm { y } \left[\lambda \mathrm { P } \left[\text { every'}^{\prime}(\lambda \mathrm{u}[\neg \operatorname{diamond}(\mathrm{u}) \wedge \mathrm{R}(\mathrm{u}) \wedge\right.\right.\right.\right. \\
& \mathrm{C}(\mathrm{u})(\mathrm{y})])(\mathrm{P})]](\mathrm{x}))(\mathrm{x})] \\
& =\lambda \mathrm{x}\left[\lambda \mathrm { Q } [ \lambda \mathrm { z } [ \mathrm { Q } \lambda \mathrm { y } [ \operatorname { s o l d } ^ { \prime } ( \mathrm { y } ) ( \mathrm { z } ) ] ] ] \left(\lambda \mathrm { P } \left[\text { every'}^{\prime}(\lambda \mathrm{u}[\neg \operatorname{diamond}(\mathrm{u}) \wedge \mathrm{R}(\mathrm{u}) \wedge\right.\right.\right. \\
& \mathrm{C}(\mathrm{u})(\mathrm{x})])(\mathrm{P})])(\mathrm{x})] \\
& =\lambda \mathrm{x}[\lambda \mathrm{z}[\lambda \mathrm{P}[\text { every'}(\lambda \mathrm{u}[\neg \operatorname{diamond}(\mathrm{u}) \wedge \mathrm{R}(\mathrm{u}) \wedge \mathrm{C}(\mathrm{u})(\mathrm{x})])(\mathrm{P})] \\
& \left.\left.\left(\lambda \mathrm{y} \cdot \operatorname{sold}^{\prime}(\mathrm{y})(\mathrm{z})\right)\right](\mathrm{x})\right]
\end{aligned}
$$




$$
=\lambda \mathrm{x}\left[\operatorname{every}^{\prime}(\lambda \mathrm{u}[\neg \operatorname{diamond}(\mathrm{u}) \wedge \mathrm{R}(\mathrm{u}) \wedge \mathrm{C}(\mathrm{u})(\mathrm{x})])\left(\lambda \mathrm{y} \cdot \operatorname{sold}^{\prime}(\mathrm{y})(\mathrm{x})\right)\right]
$$

Multiple dependencies not only involve multiple applications of the D-rule, but also multiple applications of the Geach rule. Much of the technical details for binding multiple dependencies are worked out in Jacobson (1999). In (40) below, we see the categorial result of multiple applications of the Geach rule to 'every'; and in (42) relevant parts of the interpretation of (23) are given:

$$
\begin{array}{ll}
\text { a. } & \mathrm{g}_{\mathrm{NP}}((\mathrm{S} /(\mathrm{S} / \mathrm{NP})) /(\mathrm{S} / \mathrm{NP}))=(\mathrm{S} /(\mathrm{S} / \mathrm{NP}))^{\mathrm{NP}} /(\mathrm{S} / \mathrm{NP})^{\mathrm{NP}} \\
\text { b. } & \mathrm{g}_{\mathrm{NP}}\left(\mathrm{g}_{\mathrm{NP}}((\mathrm{S} /(\mathrm{S} / \mathrm{NP})) /(\mathrm{S} / \mathrm{NP}))\right)=\left((\mathrm{S} /(\mathrm{S} / \mathrm{NP}))^{\mathrm{NP}}\right)^{\mathrm{NP}} /\left((\mathrm{S} / \mathrm{NP})^{\mathrm{NP}}\right)^{\mathrm{NP}}
\end{array}
$$

every(student' $)\left(z\left(\right.\right.$ thought $\left.^{\prime}\right)(\mathrm{g}($ no(examiner' $))\left(\mathrm{z}\left(\uparrow^{\dagger}\right.\right.$ noticed' $)(\mathrm{g}(\mathrm{g}($ every’ $))($ mi stake $\left.\left.\left.\left._{\mathrm{dd}}{ }^{\prime}\right)\right)\right)\right)$ )

$$
\begin{aligned}
& \text { a. } \quad \mathrm{z}\left({ }^{\dagger} \text { noticed' }\right)\left(\mathrm{g}\left(\mathrm{g}\left(\text { every'}^{\prime}\right)\right)\left(\text { mistake }_{\mathrm{dd}}{ }^{\prime}\right)\right) \\
& \text { b. } \quad \mathrm{g}(\text { every') }=\lambda \mathrm{R}[\lambda \mathrm{x}[\lambda \mathrm{P}[\text { every' }(\mathrm{R}(\mathrm{x}))(\mathrm{P})]]] \\
& \text { c. } \quad \mathrm{g}\left(\mathrm{g}(\text { every') })=\lambda \mathrm{G}\left[\lambda \mathrm{y}\left[\lambda \mathrm{R}\left[\lambda \mathrm{x}\left[\lambda \mathrm{P}\left[\text { every'}^{\prime}(\mathrm{R}(\mathrm{x}))(\mathrm{P})\right]\right]\right](\mathrm{G}(\mathrm{y}))\right]\right]\right. \\
& \text { d. } \quad \mathrm{g}\left(\mathrm{g}\left(\text { every' }^{\prime}\right)\right)\left(\text { mistake }_{\mathrm{dd}}{ }^{\prime}\right)= \\
& \lambda y\left[\lambda R\left[\lambda x\left[\lambda P\left[\text { every'}^{\prime}(\mathrm{R}(\mathrm{x}))(\mathrm{P})\right]\right]\right]\left(\text { mistake }_{\mathrm{dd}}{ }^{\prime}(\mathrm{y})\right)\right] \\
& =\lambda \mathrm{y}\left[\lambda \mathrm{x}\left[\lambda \mathrm{P}\left[\text { every }\left(\text { mistake }_{\mathrm{dd}}{ }^{\prime}(\mathrm{y})(\mathrm{x})\right)(\mathrm{P})\right]\right]\right] \\
& \text { e. } \quad \mathrm{z}(\uparrow \text { noticed' }) \mathrm{g}\left(\mathrm{g}\left(\text { every'}^{\prime}\right)\right)\left(\mathrm{mistake}_{\mathrm{dd}}{ }^{\prime}\right)=
\end{aligned}
$$

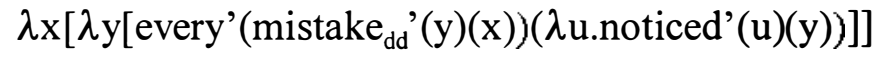

\section{Pronouns and Bindability}

As suggested above, the canonical expression which receives a bound-into interpretation is the third-person pronoun. Jacobson proposes that all pronouns are category $\mathrm{NP}^{\mathrm{NP}}$ and type $<\mathrm{e}, \mathrm{e}>$. This means that, where a pronoun is not bound (as in, "John likes her"), the root clause is interpreted as a function from individuals to truth values. The idea is that, in these cases, context makes salient an individual for the function to apply to. Although this may seem counter-intuitive, Jacobson argues that it is no more so than the more conventional account according to which, "John likes her" is interpreted relative to an assignment function. Maybe this is true. However, what would be better is a variable-free account according to which all root clauses express propositions and unbound pronouns are not $<\mathrm{e}, \mathrm{e}\rangle$ functions but simple unbound expressions (whether type <e>, or E-type).

Such an account is possible in the general framework outlined above. That is, we could say that pronouns are canonically type $<\mathrm{e}>$ or E-type and account for their bindability using the D-rule outlined above. The general idea would be that the contextual fixing of pronoun interpretation would be another case of pragmatics fixing default wild-card attributes. In terms of the above flexible-lexicon proposal, we would say that there is virtually no information in the standing lexical semantic structure for pronouns but that their interpretation is fixed via wild-cards. ${ }^{4}$

In as far as the D-rule and contextual constraint on lexical interpretation is required for an account of context dependence and bindability in general, then there 
seems to be no reason to make an exception of pronouns. According to this alternative to Jacobson's proposal, we could assume that it is a rule of the grammar that all root clauses are obligatory type $<t>$. That is, no dependencies are left unbound.

There is a good reason to suppose that the lexical mechanisms for forming dependent expressions are independently required in the case of pronouns. This comes from considering the fact that (donkey) pronouns can have multiple dependencies - as illustrated in the following example:

Context: Students can submit a paper for assessment in a given subject or sit an exam. For each subject, three examiners mark papers or exams.

a. $\quad$ Every $_{\mathrm{x}}$ student who submitted papers for assessment asked every examiner to go over them $\mathrm{x}_{\mathrm{x}, \mathrm{y}}$ with them.

b. $\quad$ them $_{x, y}=$ the papers $x$ submitted which $y$ marked

Obviously, multiple dependencies in pronouns are problematic for Jacobson's general treatment of pronouns as type $<\mathrm{e}, \mathrm{e}>$. Further problems emerge in cases such as intentional identity contexts:

John thinks a witch killed Bill's cow. Sam thinks she blighted Mary's sheep.

If we were to follow Jacobson's general programme, it seems we would have to say that the second sentence in (44) expresses a function from individual concepts, rather than individuals since it is an individual concept that context makes salient in these case, not an individual (see van Rooy \& Dekker 1998). In order to pursue a unitary account, Jacobson would then have to suppose that pronouns are $<<\mathrm{s}, \mathrm{e}>,<\mathrm{s}, \mathrm{e}>>$. But it is not so clear that individual concepts are the type of thing that are salient in the case of deictic uses of pronouns. Indeed, the general consensus about such usage of pronouns is that they are directly referential. I.e. that the individual indicated figures in the proposition expressed (and not a rigid individual concept - see Kaplan 1989).

\section{Relating Context Dependence and Bindability Generally}

On the question of the correlation between context dependence and bindability, we have seen that DRT-presupposition accounts do offer a simple story: Contextdependent expressions are presuppositional and presuppositions can be bound/accommodated in non-global DRSs. But we have also seen that there are problems to do with weak cross-over and with some of the multiple-dependency cases. The alternative offered here looks at things differently: Natural languages are inherently flexible at the lexical level - allowing for contextual restriction of lexical interpretation and for a shifting operation via something like the D-rule. While any lexical item can undergo this kind of shifting, the shifted expression of necessity undergoes some contextual restriction to relate the interpretation to elements in the binding domain. 
It was suggested above that 'green' and 'cut' could just about be construed as being bound into - but only in as far as these expressions can have contextually variable interpretations. If an expression cannot construed as contextually variable, then we do not perceive it as bindable. Thus it doesn't really feel like 'ate' in (45) could be understood as bound into without a lot of context ${ }^{5}$ :

Every boy ate before joining the others

The reason for this is simple. Although 'eat' could undergo the D-rule, it would be a redundant process unless we could think of different kinds of eating that could be related to the boys in domain. The D-rule is only perceived to apply in cases where a word's interpretation could relevantly vary with individuals in some higher binding domain. A word ('tall' or 'finish') whose interpretation is normally partly fixed by context, is obviously more amenable to shifted interpretations where relevant.

\section{Conclusion}

The traditional methodology for dealing with binding using variables seems particularly inappropriate once the full flexibility of language is taken into account. A DRT-based approach can capture something of the idea that bindability is related to context dependence. However, it seems that binding dependencies are subject to configurational constraints and so need to be represented at a syntactic level. Since DRT-presupposition accounts treat binding as a pragmatic phenomenon, any syntactic facts to do with binding are inexplicable. Also, a DRT-presupposition approach would be stretched to handle the various multiple dependency cases. It seems that the locus of flexibility where bindability is concerned is the lexicon. This in turn implies that natural language grammars allow context to heavily influence lexical interpretation.

\footnotetext{
Endnotes

${ }^{1}$ Note that, here and below, G\&vdS's proposals are not only interpolated but also misrepresented since G\&vdS employ a modified DRT framework adapted from Geurts (1995). However, these innovations bear on phenomena not related to implicit binding and we can safely illustrate the account using the standard framework.

${ }^{2}$ In this paper, basic familiarity with the categorial framework employed by Jacobson (1999) will be assumed.

${ }^{3}$ Pelletier (2003) argues that Stanley \& Szabo's compositionality argument has no force since there are many cases where the syntax of a complex phrase adds meaning to its interpretation beyond the contribution of the interpretation of the parts. Eg $\llbracket[$ red ball $] \rrbracket(\mathrm{x})=\llbracket[\mathrm{red}] \rrbracket(\mathrm{x}) \wedge \|[$ ball $] \|(\mathrm{x})$. These arguments seem less than convincing for two reasons. Firstly, the examples mentioned by Pelletier are cases where arguably there are hidden elements (eg conjunction) in the structure which contribute to the interpretation. Secondly, for modification and such cases, the contribution of the
} 
syntax would have a fixed effect on interpretation. The problem with the type of proposal under discussion is that the semantic rule itself would have to be contextually variable.

${ }^{4}$ Where pronouns are understood as 'directly referential' the value of the attribute could be being identical to $\boldsymbol{a}$ where $\boldsymbol{a}$ is a rigid term.

${ }^{5}$ One context could involve the boys having to eat some particularly horrible concoction tailor-made to their individual phobias in order to join a secret society. Asking how they performed on the task, we would understand (45) to mean not just that they ate something but that they ate their individual horror meal.

\section{References}

Copestake, A. \& A. Lascarides (1999) Default representations in constraint-based frameworks. Computational Linguistics 25.1:55-105.

Geurts, B. 1995 Presupposing. PhD Dissertation. University of Stuttgart.

Geurts, B. \& R. van der Sandt 1999. Domain restriction. In: P. Bosch \& R.A. van der Sandt (eds.), Focus: Linguistic, Cognitive, and Computational Perspectives. Cambridge University Press. 268-292.

Fodor, J.A. \& E Lepore 1998 The Emptiness of The Lexicon, Critical Reflections on J. Pustejovsky's The Generative Lexicon, in Linguistic Inquiry 29.2:269-288

Jacobson, P. 1999. Towards a variable-free semantics. Linguistics and Philosophy. 22:117-184

Kaplan, D. 1989. Demonstratives, In Themes From Kaplan (J. Almog et al. eds.) New York, OUP. 481-563.

Lascarides, A. \& A. Copestake 1998 Pragmatics \& Word Meaning J. of Linguistics. 34:387-414

Partee, B. 1989. Binding Implicit Variables in Quantified Contexts. In Papers from the 25th Regional Meeting of the CLS. Part I: The General Session. Chicago.

Pustejovsky, J. 1995. The Generative Lexicon. Cambridge, Ma. MIT Press.

van Rooy, R. \& P. Dekker 1998. Intentional Identity and Information Exchange. ITALLC '98, Proceedings.

van der Sandt, R. 1992 Presupposition projection as anaphora resolution. In Journal of Semantics. 9:333-377.

Stanley, J. 2000 Context and logical form. Linguistics and Philosophy, 23, 391-434.

Stanley, J. 2002 Nominal Restriction, in Logical Form and Language, Preyer and Peter (ed.) OUP. pp 365-88.

Stanley, J. \& Z. Szabo 2000 On quantifier domain restriction. Mind and Language 15:219-261.

Westerstahl, D. 1985 Determiners and context sets. In J. v Benthem \& A. ter Meulan (eds.) Generalised Quantifiers and Natural Language. Dordrecht: Foris. 